\title{
IT's OK TO WORK ON APPLICATIONS
}

By Ben J. Korgen

M Y HAT IS OFF to Briscoe and Evans (1993) for writing their insightful article titled "The Application of Marine Sciences in the Coming Decades." Their work does not suggest that marine scientists doing curiosity-driven basic research should drop everything and start churning out applications. It does address our need to increase the likelihood that basic marine science research done in the future does indeed have applications. The article I refer to should be required reading for everyone involved in the marine sciences, if only to build awareness and keep another important dialogue alive. Although the Briscoe and Evans article has great merit in its own right, I think that its authors' efforts and its discussion should be extended to encompass science in general, not just the marine sciences.

In my own experience, applications which help maintain a flow of environmental information to the operational U.S. Navy fleet definitely require that something must be extracted and molded from the results of basic research. Various examples of the basic research results that are eligible for use in this way are not even close to being of equal value in this enterprise, either in choice of topics or in presentation.

I would guess that for the applications I work on, about $5 \%$ of the journal articles I survey are gems that provide roughly $95 \%$ of the results I need. If the suggestions offered by Briscoe and Evans can either be implemented directly or can lead to a dialogue that eventually bears fruit such that the percentage of applicable gems is significantly increased, we can all be happy.

Throughout my reading and rereading of the article being discussed, I could not help but put my own spin on the authors' arguments. As an end result, I feel better about myself and hope that others do so too. In other words, it's OK to work on ap-

B.J. Korgen, Environmental Products and Studies Division, U.S. Naval Oceanographic Office, Stennis Space Center, MS 39522-5001, USA. plications, even if some rare individual might act condescendingly toward you for doing so.

I believe that Briscoe and Evans could improve their argument by more clearly distinguishing the applied scientist and the user. (As it stands, the reader is free to consider the applied scientist as always being the same person as the user.) I prefer to separate the user as someone who, for instance, receives a digital or hardcopy product that has been molded by applied scientists who have extracted information from basic research results. (In my experience, the user is a nonscientist planner.) When this distinction is made, one can readily discuss how the user and the applied scientist can help each other.

Using this distinction, the authors could have strengthened their list of suggestions by adding recommendations for better collaboration between users and applied scientists. Nonscientist users should, for example, routinely make known to applied scientists the kinds of graphic displays that make the most sense to them and also are compatible with the calibration of commonly used equipment. And applied scientists should routinely coach users to avoid misinterpretation of information provided (for example, so that the user does not observe the drift of objects moved by instantaneous surface currents and become angry because it does not agree with a seasonally averaged current pattern that has been provided by the applied scientist).

I hope also that whatever comes of this dialogue, the results will be integrated with both training and career planning. If applications that depend on understanding the marine environment place strong demands on optics and acoustics as well as on hydrodynamics, should we not beef up our graduate school offerings in underwater optics and acoustics? Should future oceanography professors be encouraged or even required to work on applications at the bachelors or masters degree levels before entering doctoral programs? If the latter were done, marine science professors would at least know more about what is wanted and used
Should future

oceanography

professors be

encouraged or even

required to work on

applications at the

bachelors or masters

degree levels before

entering doctoral

programs? 
. . . applications work

remains to be

done... and could therefore offer their students better examples.

Will jobs be waiting for young scientists interested in working on applications? Nobody can achieve perfection in predicting the future, but applications work remains to be done, and many applied science niches that are presently filled will eventually be emptied by retirement and other causes. This may not occur as a flood of openings, but it should nevertheless occur. Should the dictatorial chain of command often found in applied science establishments be feared and dreaded? With one exception (who would make Adolph Hitler look like a Sunday school teacher), the applied science bosses I have encountered have been easier on me than I would have been if left to my own devices.
Could someone who participates in the ultimate marine science application (helping to prevent World War III) develop into an egomaniac? Of course not. We only hear about these things in the form of self-effacing in-jokes. Molding products that are actually used, and on which someone's life might depend, is a sobering and humbling experience. In short, I would offer that applied science work in oceanography offers a significant fringe benefit: it can serve as a cure for delusions of grandeur.

\section{Reference}

Briscoe, M. and D. Evans, 1993: The application of marine sciences in the coming decades. Oceanography, 6, 138-140. 